\title{
BALANÇO SOCIAL: ESTUDO BIBLIOMÉTRICO NA BASE CAPES
}

\section{REVISÃO BIBLIOMÉTRICA}

BRAGA, lluska Lobo ${ }^{1}$

MATOS, Gleimiria Batista da Costa ${ }^{2}$

ARENAS, Marlene Valério dos Santos ${ }^{3}$

BOMBARDELLI, Joel ${ }^{4}$

NANTES, Rosalina Alves ${ }^{5}$

${ }^{1}$ Doutorado em Administração pela UNIGRANRIO; mestrado em Administração pela UNIR; pós-graduação em Gestão de Pessoas pela UNIR, graduação em Contabilidade pela Universidade Moura Lacerda.

2 Doutorado em Desenvolvimento Regional. Mestrado em Mestrado em Desenvolvimento Regional e Meio Ambiente. Especialização em Controladoria Institucional e Ambiental. Especialização em Administração Pública. Graduação em Bacharel em Ciências Contábeis.

3 Doutorado em Administração. Mestrado em Engenharia Da Produção. Especialização em andamento em Direito Médico e Proteção Jurídica Aplicada à Saúde. Especialização em Metodologia do Ensino Superior. Graduação em Direito. Graduação em Licenciatura - Esquema I. Graduação em Administração. Graduação em Ciências Contábeis.

${ }^{4}$ Doutorado em Ciências da Linguagem. Mestrado em Engenharia de Produção. Graduação em Ciências Contábeis.

5 Doutorado em andamento em Desenvolvimento Regional e Meio Ambiente. Mestrado em Administração. Especialização em Administração Publica. Graduação em Direito. 
ALMEIDA, Vanessa Fernanda Rios de ${ }^{6}$

BRAGA, lluska Lobo. Et al. Balanço Social: Estudo Bibliométrico na Base CAPES. Revista Científica Multidisciplinar Núcleo do Conhecimento. Ano 05, Ed. 10, Vol. 09, pp. 177-192. Outubro de 2020. ISSN: 2448-0959, Link de acesso: https://www.nucleodoconhecimento.com.br/administracao/base-capes

\section{RESUMO}

No Brasil por meio da Resolução CFC 1003/2004 que entrou em vigor em 2006 se estabelece diretrizes voluntárias para publicações dos aspectos ambientais e sociais das empresas, normativa que vem estimular a prática de informar ações relacionadas a Responsabilidade Social Corporativa das Empresas. Dessa forma, este estudo objetiva identificar as pesquisas científicas publicadas sobre o tema Balanço Social divulgadas na base de dados da CAPES (Coordenação de Aperfeiçoamento de Pessoal de Nível Superior) desde o seu início legal em 2006 e sua evolução nos primeiros 8 anos. Para atender o objetivo proposto se estabeleceu como objetivos específicos: identificar o volume de produção publicada sobre o tema (1), categorizar os autores mais citados e as obras referenciadas (2); e elencar as obras e autores publicados em língua estrangeira mais referendados (3). Para tanto foi realizada uma pesquisa bibliométrica, onde se obteve como principais resultados desse estudo que nesse período foram publicados 34 artigos, a autora Ribeiro aparece nessa relação com o maior quantitativo de obras referendadas enquanto os autores Tinoco; Kroetz e Ashley aparecem com expressividade de citação; o autor Deegan é o autor que se destaca como obra de língua estrangeira. Por fim, observa-se uma incipiência da pesquisa nas escolas de administração e contabilidade voltada ao tema relacionado.

\footnotetext{
${ }^{6}$ Mestrado em Administração. Especialização em Pós-Graduação Lato Sensu em Planejamento Estratégico na Gestão Pública. Especialização em MBA em Gestão Financeira, controladoria e auditoria Fiscal e Contábil. Graduação em Ciências Contábeis.
} 
Palavra-Chave: Balanço Social, Relatório de Sustentabilidade, contabilidade, Responsabilidade Social Corporativa.

\section{INTRODUÇÃO}

As organizações empresariais são consideradas vilões nas questões sociais e ambientais pois como núcleo motor do sistema capitalista tem sido responsável há um pouco mais de dois séculos pela empregabilidade, produção e estímulo ao consumo nas sociedades mundiais, e consequentemente as relações por ela estabelecidas geram consequências diretas na sociedade. Em meados do século $X X$ as relações humanas, a exploração ambiental e principalmente os resíduos provenientes da produção dessas organizações estão sendo colocados em discussão, que por sua vez, tem gerado mudanças significativas no aspectos legais no âmbito internacional e nacional.

Administrativamente a discussão ocorre no âmbito da gestão socioambiental e nas práticas que essas organizações estão efetivando frente às mudanças ocorridas na sociedade. Essas organizações requerem á Contabilidade relatórios que demonstrem essas práticas e gerem dados que apresentem as ações praticadas. No âmbito mais macro desse contexto, discute-se o desenvolvimento sustentável da sociedade onde estão contidas as organizações e a responsabilidade social corporativa das empresas.

Em resposta a sociedade, as organizações podem publicar demonstrativos contábeis voluntários denominados de Balanço Social. Esses demonstrativos surgiram nos anos 60 nos países desenvolvidos e no Brasil passou a ser discutido na década de 70 (FERREIRA et al, 2009). O autor afirma que essa é uma ferramenta de gestão para informação de Responsabilidade Social Corporativa. No Brasil, a obrigatoriedade de evidenciação dessas informações contábeis passou a ser regulamentada pela NBC T-15, aprovada através da Resolução CFC nํ⒈003, de 19/08/2004, que determina a divulgação da Demonstração de Informações de Natureza Social e Ambiental, a partir de 1ํ de janeiro de 2006 (CONSENZA; MAMEDE; DA COSTA LAURENCEL, 2010). 
O Balanço Social é um instrumento que evidencia de forma transparente informações de desempenho das entidades de cunho contábil, econômico, ambiental e social na busca do desenvolvimento sustentável (TINOCO, 2010). O autor esclarece que o relatório envolve a elaboração de cinco vértices: balanço de pessoas (1); demonstração do valor adicionado (2); inserção ambiental (3); responsabilidade social (4); atividades que as entidades exercem (5).

Devido o tema ser contemporâneo, assim como o amadurecimento das publicações científicas da área de contabilidade e administração, o estudo objetiva fazer um levantamento bibliométrico das publicações registradas na base da Coordenação de Aperfeiçoamento de Pessoal de Nível Superior (Capes) do Ministério da Educação do Brasil (MEC) que tratam do tema Balanço Social, considerando o ano de 2006 quando a normativa foi regulamentada; e identificar sua evolução nos primeiros 8 anos em face ao desafio da responsabilidade social corporativa no Brasil.

Como objetivos específicos buscou-se identificar o volume de produção publicada sobre o tema (1), categorizar os autores mais citados e as obras referenciadas (2); e elencar as obras e autores publicados em língua estrangeira mais referendada (3).

Desta forma, o estudo se propõe a realizar uma pesquisa bibliométrica das publicações nas escolas de Administração e Contabilidade; assim como traçar os autores que estão de forma seminal sendo referendados nas pesquisas científicas publicadas no sítio da rede mundial de computadores sob o domínio da CAPES[7], Para tanto, será utilizado como palavra-chave Balanço Social, sendo selecionado na busca avançada o filtro palavra exata.

As contribuições esperadas deste estudo são: (i) que a identificação dos autores nacionais e estrangeiros referendados, assim como as principais obras citadas no veículo de comunicação pesquisado, estimule e direcione a produção científica brasileira e dissemine a evolução do conhecimento de natureza contábil e administrativa (ii) seja delineado o estágio das pesquisas realizadas no Brasil após a regulamentação para a construção do conhecimento científico. 
Essa pesquisa se justifica, considerando que o primeiro trabalho sobre a produção científica em contabilidade no Brasil com foco na Epistemologia foi realizado por Theóphilo (2000) e na área de administração Martins (1994) (THEOPHILO; IUDICIBUS, 2009). Os autores esclarecem que no Brasil mais de $50 \%$ não fazem referencia a estudos anteriores e que essa ausência de discussão sobre o assunto compromete o avanço do conhecimento, pois parte-se um novo reconstruir.

No campo da administração existem vários estudos bibliométrico, mas citam Moretti e Campanario para afirmar que na área de desenvolvimento sustentável e responsabilidade social corporativa esses estudos são incipientes (MACHADO, 2012).

De acordo Gladwin, Kennelly e Krause (apud MACHADO, 2012) afirmam que o desenvolvimento sustentável é um processo do desenvolvimento humano, para tanto é necessário reconhecer a complexidade das relações entre esses sistemas e investir em inovações. Esse processo avaliado no âmbito das organizações é chamado de responsabilidade social corporativa (RSC). No Brasil esse movimento inicia-se na década de 1990 onde se destaca a Ação pela Cidadania lançada pelo sociólogo Herbert de Souza (MACHADO, 2012).

Os estudos bibliométricos sobre as pesquisas na área contábil afirma que essa produção é contemporânea e que vem se fortalecendo a partir de 2000, onde apresenta como hipótese desse avanço o crescimento dos cursos de stricto sensu no Brasil. Apesar da taxa de crescimento ser menor que em outros ramos do conhecimento (ESPEJO et al, 2009).

\section{PROCEDIMENTOS METODOLOGICOS}

Este estudo tem como objetivo analisar a produção científica sobre Balanço Social publicada pelos pesquisadores das academias de Administração e Contabilidade desde 2003, quando entra em vigor a resolução CFC 1003/2004, e sua evolução nos próximos 8 anos. A pesquisa foi desenvolvida na base de dados disponível no sítio da CAPES. 
Como procedimento metodológico utilizou a bibliometria como a técnica de pesquisa para quantificação, avaliação e analise da produção científica. Essa técnica auxilia na identificação das informações importantes e das principais obras que influenciam a produção cientifica em estudo (RIBEIRO; COSTA, 2012).

Egghe (apud RIBEIRO; COSTA, 2012) esclarece que a bibliometria desenvolveu-se com base no comportamento da literatura que pode ser definido em três leis empíricas: Brandford, Lotka e Zipf. O estudo em questão foi influenciado na lei de Lotka que descreve a produtividade e citações de autores. Para investigar a produção cientifica desse período foi utilizado a palavras chaves exata Balanço Social registrada nos assuntos das publicações.

Para fins metodológicos essa pesquisa ocorreu em três etapas: O levantamento do banco de dados da CAPES dos artigos disponíveis (1); análise das referências, onde serão categorizadas as referências (2); análise bibliométrica onde será quantificada as informações identificadas (3). Na Figura 1 está demonstrado as etapas da pesquisa.

Figura 1: Etapas da pesquisa

\section{Análise do assunto}

\section{Análise bibliométrica}

\section{Análise das referências}

- Seleção de artigos no sítio da capes no periodo de 2003 a 2013 com contenham a expressão balanço social

- Quantificação das obras e autores nacionais e de língua estrangeira referendados nas publicações

-Análise das referencias utilizadas pelos estudos da área contábil e da administração.

Fonte: Elaboração própria

A análise bibliométrica dos artigos será efetivada com base nos seguintes indicadores: I) evolução das publicações no período; II) obras mais citadas; III) autores com maior produção; IV) publicação em língua estrangeira; V) obras de língua estrangeira mais citada; VI) autores de língua estrangeira mais referendados. 


\section{RESULTADO E DISCUSSÃO}

Para a análise do assunto, a pesquisa identificou o volume de 33 produções publicadas sobre o tema balanço social durante o período de 2003 a 2013. No Quadro 1 , está descrita a distribuição em ordem decrescente de ano, categorizada entre artigos e teses.

Quadro 1: Volume produção 2006 a 2013

\begin{tabular}{|l|l|l|l|l|}
\hline ANOS & ARTIGO & TESE & TOTAL GERAL & $\%$ \\
\hline 2013 & 2 & 0 & 2 & $6 \%$ \\
\hline 2012 & 3 & 0 & 3 & $9 \%$ \\
\hline 2011 & 6 & 0 & 6 & $18 \%$ \\
\hline 2010 & 6 & 1 & 7 & $21 \%$ \\
\hline 2009 & 3 & 3 & 6 & $18 \%$ \\
\hline 2008 & 3 & 1 & 4 & $12 \%$ \\
\hline 2007 & 2 & 2 & 4 & $12 \%$ \\
\hline 2006 & 1 & 0 & 1 & $3 \%$ \\
\hline 2005 & 0 & 0 & 0 & $0 \%$ \\
\hline 2004 & 0 & 0 & 0 & $0 \%$ \\
\hline 2003 & 0 & 0 & 0 & $0 \%$ \\
\hline 2002 & 0 & 1 & 1 & $3 \%$ \\
\hline TOTAL & 26 & 8 & 34 & $100 \%$ \\
\hline
\end{tabular}

Fonte: autoria própria

Apesar do filtro no sistema estabelecer o ano início de 2003, o sistema trouxe uma tese de 2002, ano anterior a regulamentação. Mas as publicações passam a ocorrer em 2006 ano que a regulamentação entra em vigor. A publicação de 2002 foi desconsiderada para fins de análise, dessa forma está se trabalhando com 33 publicações para o período de 2003 a 2013. 


\subsection{VOLUME DE PRODUÇÃO}

Para analisar a evolução das publicações no sítio da CAPES no período proposto foi utilizado o quantitativo percentual de publicação por ano, conforme gráfico 1.

Gráfico 1: Evolução da Publicação

\section{publicação}

घublicação

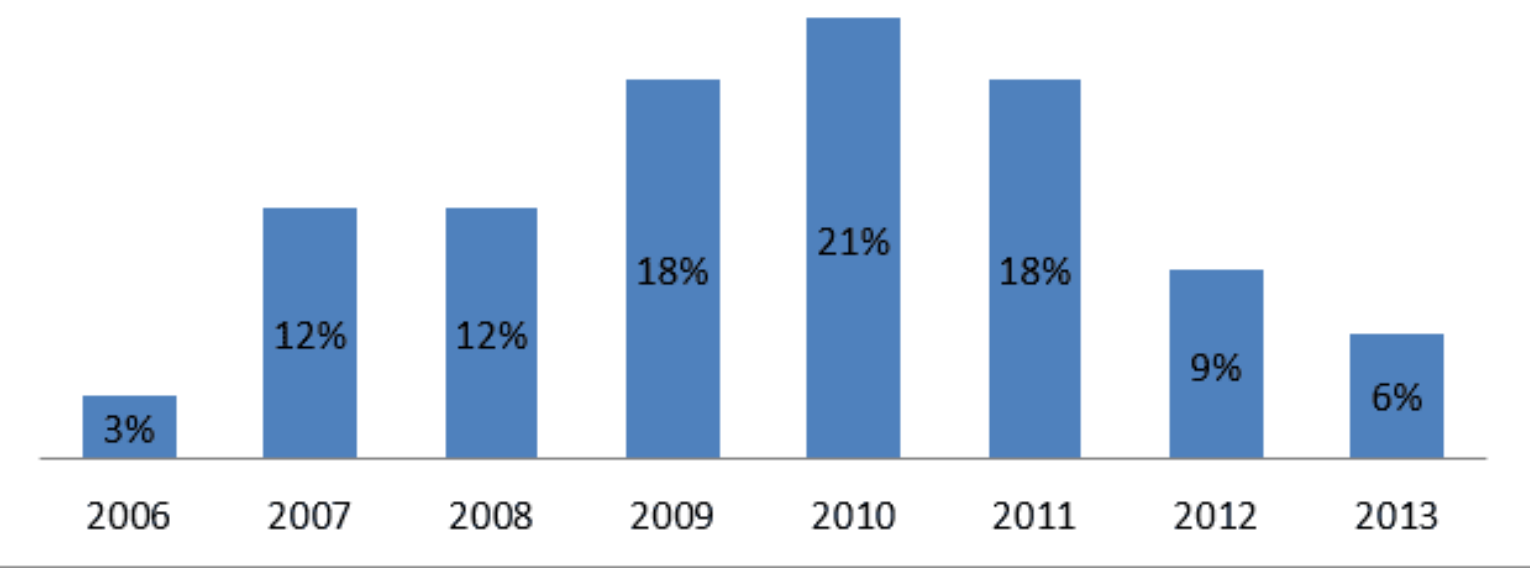

Fonte: autoria própria

As publicações analisadas estão numa crescente quando da regulamentação em 2006 até 2011, enquanto hipótese para esse crescimento das publicações nesse primeiro período é a Conferência da ONU sobre o Desenvolvimento Sustentável (RIO+20) que ocorreu no Rio de Janeiro em 2012 Posteriormente observa-se diminuição na publicação de artigos sobre essa temática.

Entretanto, quando se analisa a média de 4,25 de publicações por ano, identifica-se um quantitativo ainda baixo se pesquisa sobre o tema. Esse dado corrobora com as pesquisas bibliométricas de Machado et al. (2013); Espejo et al (2009); entre outros autores que apontam a incipiência da pesquisa nas escolas de administração e 
contabilidade voltada ao tema relacionado ao desenvolvimento sustentável, meio ambiente, e nesse estudo Balanço Social.

\subsection{CATEGORIZAÇÃO DOS AUTORES CITADOS E AS OBRAS REFERENCIADAS}

Para realizar a análise das referências utilizadas nas publicações foi estabelecido um recorte para analise apenas dos artigos publicados, considerando-se que as teses são estudos que foram publicados em revistas. Dessa forma foram analisadas as referências dos 26 artigos no período de 2006 a 2013.

Inicialmente foi feito um levantamento de todos autores citados, que foram tratados no Gráfico 2 como: números absolutos (665). Na sequência foram excluídas obras repetidas, sendo assim, se quantificou 520 autores, que no Gráfico 2 estão tratados como: números relativos (520).

Gráfico 2: Perfil da publicação referenciada

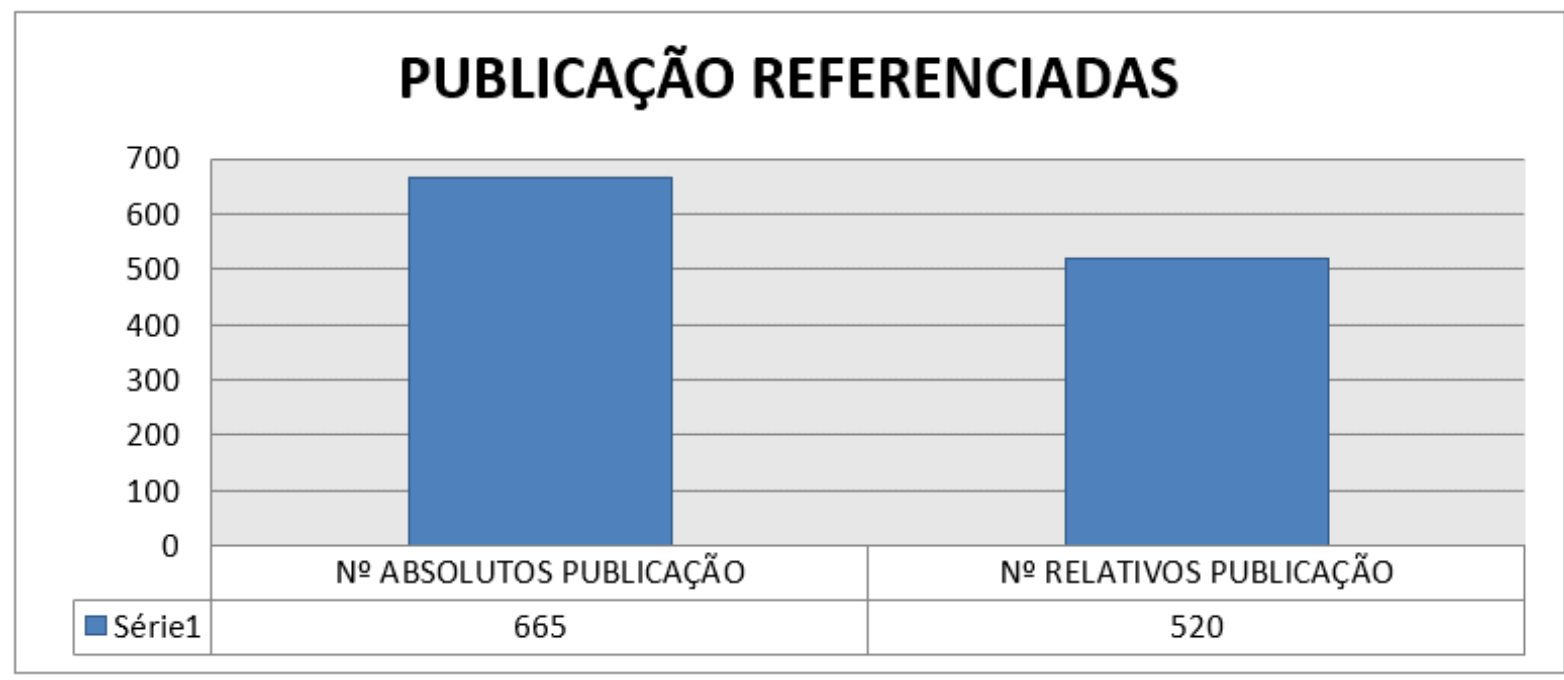

Fonte: autoria própria

Também foi levantado o quantitativo de publicação nacional (467) e em línguas estrangeiras - inglês e espanhol (53), apresentado no Gráfico 3; esse procedimento visa avaliar o quantitativo realmente citado de autores e delimitar o campo de autorias referendadas que serão estudadas. 
Gráfico 3: Origem da publicação

\section{\% ORIGEM DA PUBLICAÇÃO}

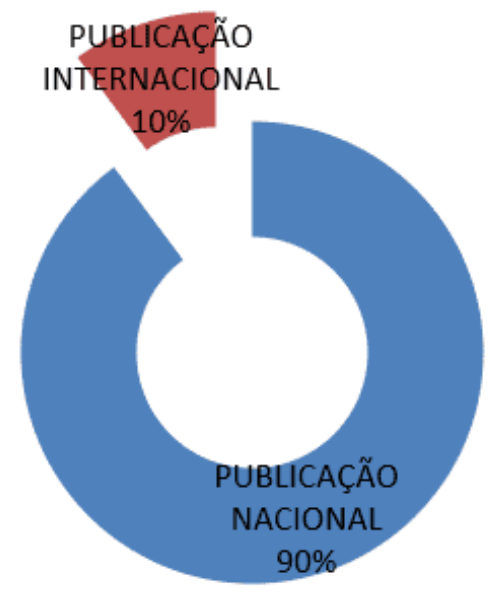

Fonte: Própria autoria

\subsubsection{PUBLICAÇÃO NACIONAL}

As publicações realizadas em língua portuguesa foram quantificadas de acordo com a ocorrência de referências considerando-se apenas o primeiro autor da publicação, sem correlacionar as coautorias estabelecidas na produção científica. Em seguida, foi reorganizado a amostra por obras referenciadas. Dessa forma, foi identificado que existem autores bastante citados, porém quando analisamos por obra, as mesmas são diversificadas. No Gráfico 4, demonstra-se em percentual as distribuições das publicações nacionais por citação referenciada. 
Gráfico 4: Percentual de obras por citação

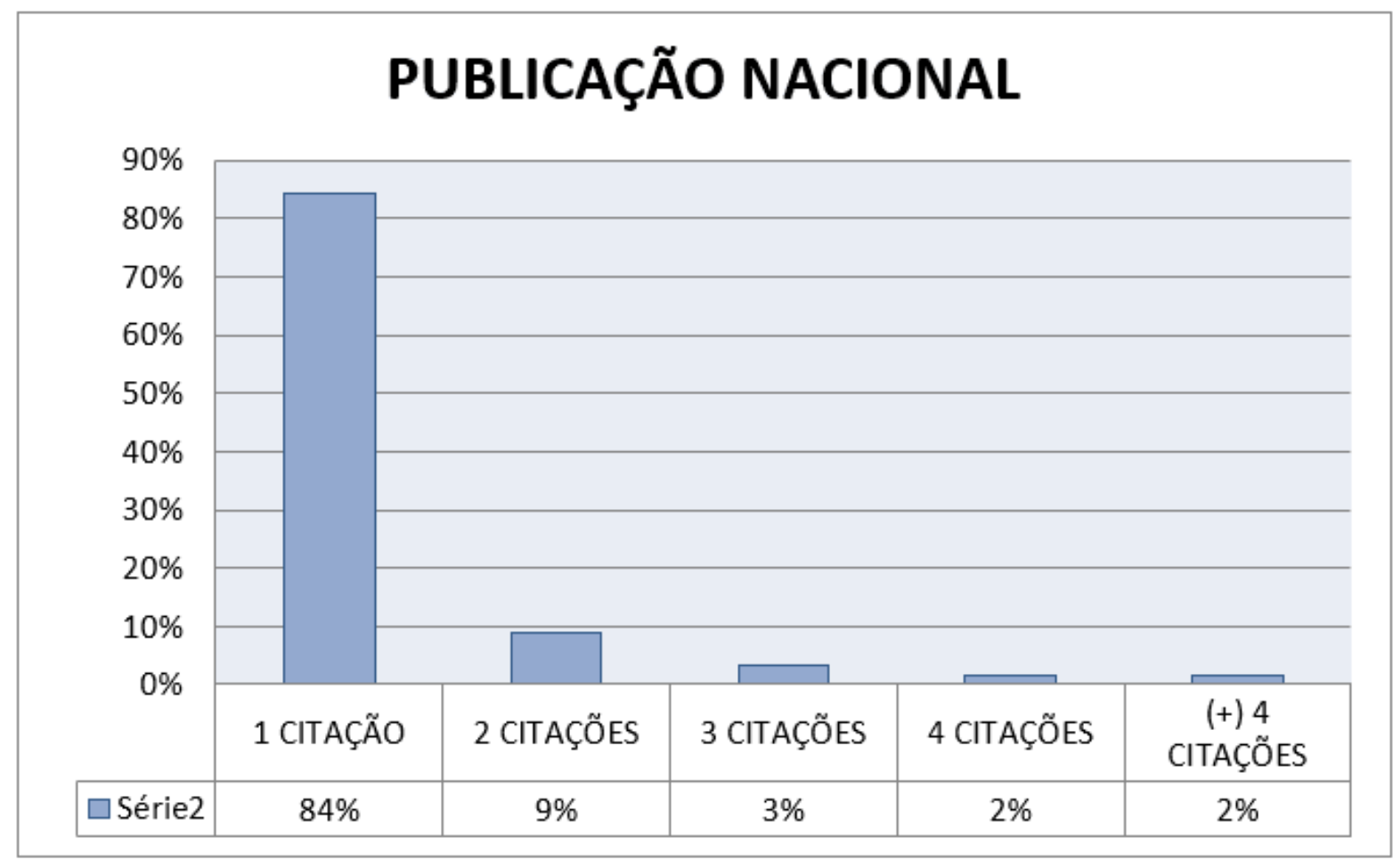

Fonte: autoria própria

Observa-se no Gráfico 4 que os estudos são com autores diversos, ou seja, $84 \%$ das referências só foram utilizadas uma única vez na pesquisa, o que demonstra que o estudo está buscando fontes interdisciplinares, em outras áreas da ciência para fundamentar os estudos em questão.

Para as obras citadas em mais de 5 pesquisas que compõem o escopo desse estudo, consideramos que há uma relevância desses autores para o campo em estudo. $\mathrm{Na}$ Tabela 1 foram sistematizadas as obras, assim como a quantidade de citações recebidas.

Tabela 1: Obras Nacionais mais citada

OBRAS NACIONAIS REFERENDADAS

AUTOR

QUANTIDADE CITAÇÕES 


\begin{tabular}{|c|c|c|}
\hline $\begin{array}{l}\text { Balanço Social: uma abordagem da } \\
\text { transparência e da responsabilidade pública } \\
\text { das organizações. }\end{array}$ & $\begin{array}{l}\text { TINOCO, João } \\
\text { Eduardo } \\
\text { Prudêncio. }\end{array}$ & 12 \\
\hline $\begin{array}{l}\text { Ética e Responsabilidade Social nos } \\
\text { Negócios. }\end{array}$ & $\begin{array}{l}\text { ASHLEY, } \\
\text { Patrícia } \\
\text { Almeida }\end{array}$ & 10 \\
\hline Balanço social: teoria e prática. & $\begin{array}{l}\text { KROETZ, } \\
\text { César } \\
\text { Eduardo } \\
\text { Stevens. }\end{array}$ & 9 \\
\hline Balanço social: teoria e prática. & $\begin{array}{l}\text { SILVA, César } \\
\text { Augusto } \\
\text { Tibúrcio; } \\
\text { FREIRE, } \\
\text { Fátima } \\
\text { de Souza }\end{array}$ & 6 \\
\hline $\begin{array}{l}\text { Uma } \\
\text { dos balanços sociais das } 500 \text { maiores. }\end{array}$ & $\begin{array}{l}\text { OLIVEIRA, } \\
\text { José Antônio } \\
\text { Puppim. }\end{array}$ & 6 \\
\hline $\begin{array}{l}\text { Responsabilidade social das empresas e } \\
\text { balanço social: meios propulsores do } \\
\text { desenvolvimento econômico e social. }\end{array}$ & $\begin{array}{l}\text { REIS, Carlos } \\
\text { Nelson dos; } \\
\text { MEDEIROS, } \\
\text { Luiz Edgar. }\end{array}$ & 5 \\
\hline
\end{tabular}

Fonte: autoria própria

Analisando a tabela destaca-se a obra de Tinoco, Balanço Social, uma abordagem da transparência e da responsabilidade pública das organizações, como uma obras nacional, e seminal dentro da temática de Balanço Social. 


\subsubsection{AUTORES REFERENDADOS NAS OBRAS NACIONAIS}

Devido a diversificação das obras referendadas por autores, foram considerados os autores com maior produção os que tiveram mais de quatro citações independente da obra, ou seja, os autores que têm elaborado pesquisa sobre o tema e influenciado a pesquisa sobre o balanço social, conforme Tabela 2. Cabe ressaltar que não foi considerado como autores instituições tais como: Brasil - Regulamentações e Leis; Capes - Regulamentações e pesquisas; Instituto Brasileiro de Análises Sociais e Econômicas (IBASE) - orientações sobre publicação de balanço social; Instituto Ethos de Empresas e Responsabilidade Social (ETHOS) orientações sobre publicação de balanço social, entre outros.

Tabela 2: Autores com maior produção

\begin{tabular}{|l|l|l|}
\hline $\begin{array}{l}\text { AUTORES NACIONAIS } \\
\text { REFERENDADOS }\end{array}$ & $\begin{array}{l}\text { QUANTITATIVO } \\
\text { OBRAS CITADAS }\end{array}$ & $\begin{array}{l}\text { QUANTITATIVO } \\
\text { CITAÇÕES } \\
\text { RELATIVA }\end{array}$ \\
\hline $\begin{array}{l}\text { TINOCO, João Eduardo } \\
\text { Prudêncio. }\end{array}$ & 3 & 14 \\
\hline $\begin{array}{l}\text { KROETZ, César Eduardo Stevens. } \\
\text { ASHLEY, Patrícia Almeida }\end{array}$ & 3 & 11 \\
\hline $\begin{array}{l}\text { TORRES, Ciro. } \\
\text { OLIVEIRA, José Antônio Puppim. }\end{array}$ & 3 & 10 \\
\hline $\begin{array}{l}\text { RIBEIRO, Maísa de Souza. } \\
\text { IUDÍ́CIBUS, Sérgio de. }\end{array}$ & 5 & 8 \\
\hline $\begin{array}{l}\text { SILVA, César Augusto Tibúrcio; } \\
\text { FREIRE, Fátima de Souza }\end{array}$ & 1 & 7 \\
\hline $\begin{array}{l}\text { PEROTTONI, Marco Antônio } \\
\text { REIS, Carlos Nelson dos; } \\
\text { MEDEIROS, Luiz Edgar. }\end{array}$ & 1 & 6 \\
\hline
\end{tabular}

Fonte: autoria própria 
A autora Ribeiro aparece nessa relação com o maior quantitativo de obras referendadas enquanto os autores Tinoco; Kroetz e Ashley aparecem com expressividade de citação entre autores estudados.

Convém destacar que se identificam autores com quantitativos acima de quatro citações, mas isso é devido a um grande quantitativo de obras do mesmo autor utilizadas em um único artigo, como por exemplo Baldissera; Morin, citados em um artigo. Esse fato denota identificação de determinado pesquisador com a obra, sendo desconsiderado neste estudo.

\subsection{PUBLICAÇÃO EM LÍNGUA ESTRANGEIRA}

Como analisado anteriormente $10 \%$ (dez por cento) dos trabalhos referenciados nas publicações analisadas são texto ou na língua inglesa ou na língua espanhola. Inicialmente foi levantado o quantitativo de citações estabelecidas para análise do universo pesquisado conforme Gráfico 5.

Gráfico 5: Citações Língua Estrangeira

\section{PUBLICAÇÃO INTERNACIONAL}

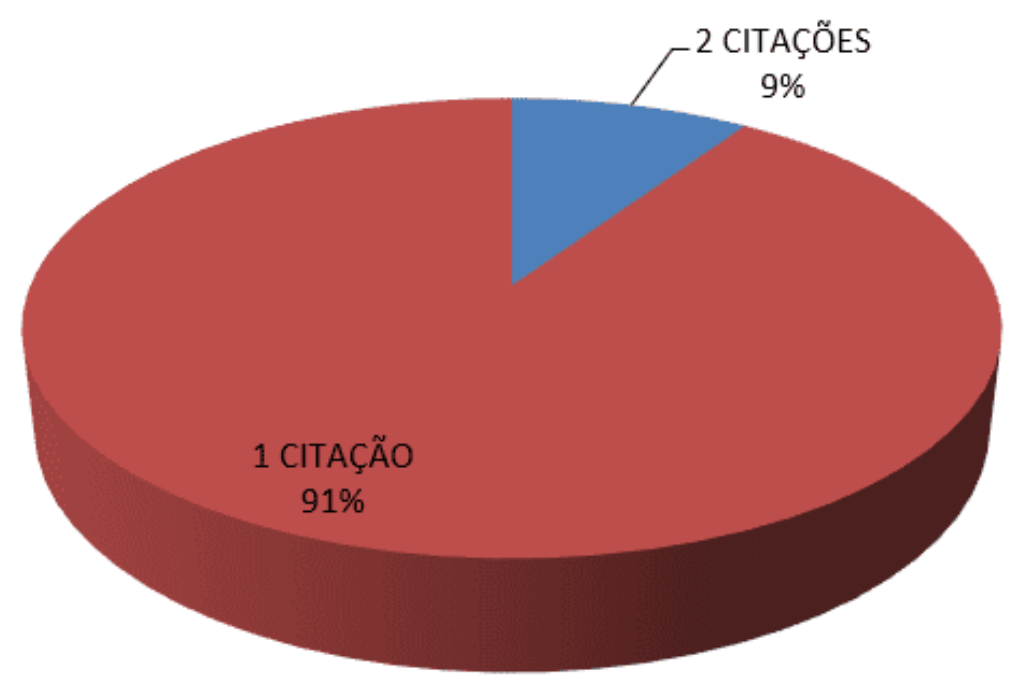

Fonte: Autoria Própria 
Novamente, observa-se uma pulverização das citações, onde $91 \%$ das pesquisas utilizam autores que não são citados em outras obras. As 5 (cinco) obras com mais de 1 (uma) citação são em língua inglesa. Destaca-se o autor Deegan que tem duas obras citada, conforme Tabela 3.

Tabela 3: Obras em Língua Estrangeira

\begin{tabular}{|c|c|c|}
\hline $\begin{array}{l}\text { OBRAS LÍNGUA ESTRANGEIRA } \\
\text { REFERENDADAS }\end{array}$ & AUTOR & $\begin{array}{l}\text { QUANTIDA } \\
\text { DE } \\
\text { CITAÇÕES }\end{array}$ \\
\hline $\begin{array}{l}\text { Stakeholder influence on corporate } \\
\text { reporting: an exploration }\end{array}$ & $\begin{array}{l}\text { DEEGAN, C.; BLOMQUIST, } \\
\text { C. }\end{array}$ & 2 \\
\hline $\begin{array}{l}\text { An Examination of the Corporate } \\
\text { Social and Environmental } \\
\text { Disclosures of BHP from 1983- } \\
\text { 1997: A test of legitimacy theory. }\end{array}$ & $\begin{array}{l}\text { DEEGAN, C.; RANKiN, M.; } \\
\text { TOBIN, J. }\end{array}$ & 2 \\
\hline $\begin{array}{l}\text { Should } \\
\text { responsibility Be Taken as "Strat } \\
\text { egic"? A Critical Approach. }\end{array}$ & $\begin{array}{l}\text { FARIA, A.; SAUERBRONN } \\
\text {, F. F. }\end{array}$ & 2 \\
\hline $\begin{array}{l}\text { Toward a theory of corporate social } \\
\text { accounting. }\end{array}$ & $\begin{array}{l}\text { RAMANATHAN, } \\
\text { KAVASSERI V. }\end{array}$ & 2 \\
\hline $\begin{array}{l}\text { Corporate social performance } \\
\text { revisited. Academy of Management } \\
\text { Review, v. }\end{array}$ & WOOD, D. J. & 2 \\
\hline
\end{tabular}

Fonte: autoria Própria

Assim como a análise feita com os autores nacionais, foi levantado o quantitativo de obras referendadas entre os pesquisados analisados neste estudo. Na tabela 4 é apresentado a quantificação das obras citadas por autor. 
Tabela 4: Obras em Língua Estrangeira

\begin{tabular}{|l|l|l|l|}
\hline $\begin{array}{l}\text { Autores } \\
\text { Estrangeira } \\
\text { Referendados }\end{array}$ & $\begin{array}{l}\text { Quantitativo } \\
\text { Obras Citadas }\end{array}$ & $\begin{array}{l}\text { Quantitativo } \\
\text { Citações Absoluta }\end{array}$ & $\begin{array}{l}\text { Quantitativo } \\
\text { Citações Relativa }\end{array}$ \\
\hline DEEGAN, C.; & 6 & 8 & 5 \\
\hline CARROL, A. B. & 3 & 3 & 2 \\
\hline WOOD, D. J. & 2 & 3 & 2 \\
\hline CHARNES, A.; & 2 & 2 & 1 \\
\hline
\end{tabular}

Fonte: autoria Própria

Analisando a quantidade de obras citadas, observa-se que o autor Deegan tem uma expressividade de obras maior do que a autora Ribeiro em língua portuguesa, sendo o autor que se destaca nesse estudo.

\section{CONSIDERAÇÕES FINAIS}

Identificou-se um quantitativo ainda baixo se pesquisa sobre o tema Balanço Social. Esse dado corrobora com as pesquisas bibliométricas dos autores Machado et al. (2013); Espejo et al (2009); que apontam a incipiência da pesquisa nas escolas de administração e contabilidade voltada ao tema relacionado ao desenvolvimento sustentável, meio ambiente, e nesse estudo Balanço Social.

$\mathrm{Na}$ análise das referências utilizadas, $90 \%$ das pesquisas se baseiam em autores nacionais, contudo observa-se que os estudos são com autores diversos, ou seja, $84 \%$ das referências só foram utilizadas uma única vez na pesquisa. Destacando a obra nacional de 'Tinoco, Balanço Social, uma abordagem da transparência e da responsabilidade pública das organizações' o trabalho mais referendado nesta pesquisa, e a autora Maísa de Souza Ribeiro, como a autora com maior produção sobre o tema, um total de 5 obras referendadas neste estudos.

Os autores que publicaram em língua estrangeira, observa-se o mesmo fenômeno que ocorreu com os autores nacionais, ou seja, $91 \%$ dos autores utilizados só foram 
citados uma única vez. Destaca-se o autor Deegan que tem seis obras referendadas nesta pesquisa.

Por fim, observa-se uma baixa adesão no campo a pesquisas sobre esse tema. Para tanto, cabe como investigação futura: (a) verificar se esse padrão se mantem na atualidade; (b) levantar quantas empresas brasileiras estão publicando os Balanço Sociais. A sustentabilidade é uma preocupação da sociedade onde há uma expectativa faça parte da perspectiva de gestão no ambiente empresarial.

\section{REFERÊNCIAS}

COSENZA, José Paulo; MAMEDE, Eurídice; DA COSTA LAURENCEL, Luiz. Análise dos fundamentos teóricos associados à pesquisa contábil na área ambiental. DOI: 10.4025/enfoque. v29i1. 10359. Enfoque: Reflexão Contábil, v. 29, n. 1, p. 18-38, 2010. Disponível: http://eduem.uem.br/ojs/index.php/Enfoque/article/view/10359. Acesso: 18.07.2014.

ESPEJO, Marcia Maria dos Santos Bortolocci. Et al. Estado da arte da pesquisa contábil: um estudo bibliométrico de periódicos nacional e internacionalmente veiculados entre 2003 e 2007. Revista de Informação Contábil. Vol. 3, n. 3, p. 94-116, jul-set/2009. Disponível: http://www.repositorio.furg.br:8080/handle/1/3935. Acesso: 15.08.2014

FERREIRA, Luiz Felipe et al. Indicadores de Sustentabilidade Empresarial: uma comparação entre os indicadores do balanço social IBASE e relatório de sustentabilidade segundo as diretrizes da global reporting initiative GRI. Simpósio de Excelência em Gestão e Tecnologia, 2009. Disponível: http://info.aedb.br/seget/artigos09/445_445_Contabilidade_social_REV.seget[2].pdf. Acesso: 18.07.2014 às $15 \mathrm{~h}$

MACHADO, Diego de Queiroz, et al. Desenvolvimento sustentável e responsabilidade social corporativa: Um estudo da produção científica brasileira. Revista Brasileira de Administração Científica. Aquidabã, v. 3, n. 3, jul - dez 2012. Disponível: 
http://www.sustenere.co/journals/index.php/rbadm/article/view/ESS2179684X.2012.003.0012. Acesso: 15.08.2014.

RIBEIRO, Henrique César Melo. COSTA, Benny Kramer. Brazilian Administration Review: uma análise do perfil da produção acadêmica científica no período de 2004 a 2012 sob a ótica da rede social e da bibliometria. Revista de Gestão, finanças e contabilidade, $\quad$ v. $2, \quad$ n. 3 , $\quad$ p. 86-104, 2012 . Disponível: http://revistas.uneb.br/index.php/financ/article/view/90. Acesso: 15.08.2014

THEÓPHILO, Carlos Renato. IUDÍCIBUS, Sergio de. Uma análise críticoepistemológica da produção cientifica em contabilidade no Brasil. Contabilidade, Gestão e Governança. V. 8, n. 2, $2009 . \quad$ Disponível: http://scholar.google.com.br/scholar?hl=pt-

$\mathrm{BR} \& \mathrm{q}=\mathrm{Uma}+\mathrm{An} \% \mathrm{C} 3 \% \mathrm{~A} 1$ lise $+\mathrm{Cr} \% \mathrm{C} 3 \% \mathrm{ADtico}-$ Epistemol\%C3\%B3gica+da+Produ\%C3\%A7\%C3\%A30+Cient\%C3\%ADfica+em+Co ntabilidade+no+Brasil\&btnG=\&lr=, Acesso: 15.08 .2014

TINOCO, João Eduardo Prudêncio. Balanço social e o relatório da sustentabilidade. São Paulo: Atlas, 2010. ISBN 978.85224.6036.6

\section{APÊNDICE - REFERÊNCIA DE NOTA DE RODAPÉ}

7. http://www-periodicos-capes-gov-br.ez8.periodicos.capes.gov.br

Enviado: Maio, 2020.

Aprovado: Outubro, 2020. 